\title{
Intrapartum Electronic Fetal Heart Rate Monitoring and the Prevention of Perinatal Brain Injury
}

\author{
Ernest M. Graham, MD, Scott M. Petersen, MD, Dana K. Christo, MPH, and Harold E. Fox, MD, MSc
}

OBJECTIVE: Electronic fetal heart rate monitoring (EFM) is the most widely used method of intrapartum surveillance, and our objective is to review its ability to prevent perinatal brain injury and death.

DATA SOURCES: Studies that quantified intrapartum EFM and its relation to specific neurologic outcomes (seizures, periventricular leukomalacia, cerebral palsy, death) were eligible for inclusion. MEDLINE was searched from 1966 to 2006 for studies that examined the relationship between intrapartum EFM and perinatal brain injury using these MeSH and text words: "cardiotocography," "electronic fetal monitoring," "intrapartum fetal heart rate monitoring," "intrapartum fetal monitoring," and "fetal heart rate monitoring."

METHODS OF STUDY SELECTION: This search strategy identified 1,628 articles, and 41 were selected for further review. Articles were excluded for the following reasons: in case reports, letters, commentaries, and review articles, intrapartum EFM was not quantified, or specific perinatal neurologic morbidity was not measured. Three observational studies and a 2001 meta-analysis of 13 randomized controlled trials were selected for determination of the effect of intrapartum EFM on perinatal brain injury.

TABULATION, INTEGRATION, AND RESULTS: Electronic fetal monitoring was introduced into widespread clinical practice in the late 1960s based on retrospective studies comparing its use to historical controls where auscultation was performed in a nonstandardized manner. Casecontrol studies have shown correlation of EFM abnormalities with umbilical artery base excess, but EFM was not able to identify cerebral white matter injury or cerebral

From the Department of Gynecology and Obstetrics, Division of Maternal-Fetal Medicine, Johns Hopkins University School of Medicine, Baltimore, Maryland; and Department of Epidemiology, Bloomberg School of Public Health, Johns Hopkins University, Baltimore, Maryland.

Corresponding author: Ernest M. Graham, MD, Johns Hopkins Hospital, Department of Gyn-Ob, Phipps 220, 600 N. Wolfe Street, Baltimore, MD 21287-1228; e-mail: egrahaa@jhmi.edu.

(C) 2006 by The American College of Obstetricians and Gynecologists. Published by Lippincott Williams \& Wilkins.

ISSN: 0029-7844/06 palsy. Of 13 randomized controlled trials, one showed a significant decrease in perinatal mortality with EFM compared with auscultation. Meta-analysis of the randomized controlled trials comparing EFM with auscultation have found an increased incidence of cesarean delivery and decreased neonatal seizures but no effect on the incidence of cerebral palsy or perinatal death.

CONCLUSION: Although intrapartum EFM abnormalities correlate with umbilical cord base excess and its use is associated with decreased neonatal seizures, it has no effect on perinatal mortality or pediatric neurologic morbidity.

(Obstet Gynecol 2006;108:656-66)

n 2002, approximately $85 \%$ of the 4 million live births in the United States were assessed with electronic fetal monitoring (EFM), making it the most common obstetric procedure. ${ }^{1}$ Electronic fetal monitoring during labor plays a central role in the current litigation crisis in obstetrics. This issue recently gained widespread attention in the lay press when in 2004 one of the candidates for president of the United States, a successful plaintiff's attorney, published a book justifying his entry into politics that expounded upon four successful trials that had occurred over the course of his career before his retirement from the practice of law at the age of 45 with an estimated personal worth of up to $\$ 70$ million dollars. ${ }^{2,3}$ Of the four trials discussed in this book, two are medical malpractice cases, of which one is a case of an infant with cerebral palsy where it is alleged that delivery should have occurred sooner because of abnormalities in the electronic fetal heart rate (FHR) tracing. Case 2 in the book, the delivery of Jennifer C., occurred in 1979 and was a total breech extraction of a term infant from a footling breech presentation. ${ }^{2}$ This infant had Apgar scores of 1 and 2 at one and five minutes, a fractured clavicle, required emergency neonatal resuscitation, developed seizures, and was diagnosed with cerebral palsy 3 months after leaving 
the hospital. Although not mentioned in the initial telling of the delivery story, later during the trial it is stated that "metal forceps" had been applied to the "emerging head." ${ }^{2}$ For attempting a vaginal delivery of a term footling breech infant rather than performing a cesarean, the delivering obstetrician settled for $\$ 1.5$ million in 1985 . If the case had ended here, it would have been an unremarkable medical malpractice case, but in an attempt to sue the hospital the plaintiff changed this case from one of birth trauma to one of hypoxia-ischemia manifested for hours before delivery in the electronic FHR tracing. In his book this plaintiff's attorney states that "First, I had to become an overnight expert in fetal monitor readings." ${ }^{2} \mathrm{He}$ states that there were "variable decelerations on the monitor strip that indicated cord compression." In closing arguments at trial he states that "...(the fetus) did everything she knew how to do...to speak to the hospital, and the only way she knew how to do it was through that strip.... At five-thirty she said 'I need out.' At six the cries got weaker. . and the cries heard were the cries of Jennifer C. dying. ... .But now she speaks to you, not through a fetal monitor strip; she speaks to you (the jury) through me." ${ }^{2}$ The jury returned a $\$ 6.5$ million verdict against the hospital. Because of the extensive clinical use of EFM and its involvement in litigation, the objective of this review is to estimate how effective intrapartum EFM is in preventing perinatal brain injury or death.

\section{SOURCES}

We sought to identify studies that assessed the relationship between intrapartum EFM and perinatal neurologic morbidity. Eligibility for inclusion was determined by the following criteria: studies had to report quantification of FHR using intrapartum EFM and assess outcomes related to brain injury (ie, seizures, periventricular leukomalacia, cerebral palsy, death). We searched MEDLINE for English language articles from January 1966 to April 2006 using the following search terms as Medical Subject Headings (MeSH) and text words as appropriate: "cardiotocography" (as $\mathrm{MeSH}$ term and text word), "electronic fetal monitoring" (text words), "intrapartum fetal heart rate monitoring" (text words), "intrapartum fetal monitoring" (text words), and "fetal heart rate monitoring" (text words).

\section{STUDY SELECTION}

This search strategy identified 1,628 articles. Articles were excluded for the following reasons: in case reports, letters, commentaries, and review articles, electronic fetal monitoring was not evaluated as the intervention, perinatal brain injury was not the main outcome, or some combination of the aforementioned factors. Abstracts were reviewed by two investigators, and 41 articles met the criteria for further review. Two investigators independently reviewed full-text articles and determined study eligibility. Of the 41 studies, 13 were excluded because they were randomized clinical trials that were included in later meta-analyse $\mathrm{s}^{4,5}$ and a more recent Cochrane Review that was selected for analysis. ${ }^{6}$ Of the remaining 28 studies, 12 were excluded because of lack of identification of a specific neurologic outcome, 10 because of the lack of a quantitative EFM parameter, one because it was unclear how patients were divided into high and low risk groups, one because it was a synthesis of randomized and nonrandomized trials, and one because birth asphyxia was defined by a 5-minute Apgar score less than 7 rather than by using a cord gas assessment. Three observational studies met the inclusion criteria for this review (Table 1). ${ }^{7-9}$ Reference lists from relevant original research and review articles were manually searched for additional studies. A description of the studies that met eligibility criteria is presented in this article within the historical context of EFM. Data from these observational studies were not combined because of differences in measured outcomes.

\section{RESULTS}

The common practice of monitoring the FHR during labor was stimulated by William Little, a London orthopedic surgeon caring for spastic infants, who in 1862 expressed the view that "the process of birth was responsible for the pathology of cerebral palsy." 10 The FHR of the laboring woman was traditionally auscultated during labor with either a stethoscope or fetoscope, but during the late 1950s research into external and internal methods to monitor the FHR during labor began to be developed. Edward Hon of Yale University and subsequently of the University of Southern California was a physician and engineer who conceived the "internal" monitor and invented the electrode, which made it possible to connect the fetus to the machine to collect the electrocardiographic information. ${ }^{11}$ Roberto Caldeyro-Barcia in Montevideo, using a paper speed of $1 \mathrm{~cm} / \mathrm{min}$, identified 2 types of FHR decelerations: type 1 dips were simultaneous with uterine contractions, and type 2 dips (late decelerations) persisted after the contraction had ended. Type 1 decelerations were not associated with fetal depression at birth, but type 2 decelerations were. ${ }^{12}$ Using a faster recording speed of $3 \mathrm{~cm} / \mathrm{min}$, Hon was able to differentiate 3 patterns of FHR 
Table 1. Studies Quantitating the Relationship Between Intrapartum Electronic Fetal Monitoring and Neurologic Morbidity

\begin{tabular}{|c|c|c|c|c|}
\hline Study & Date & Design & $\mathrm{N}$ & Neurologic Outcomes \\
\hline \multirow[t]{4}{*}{ Yeh et $\mathrm{al}^{7}$} & 1982 & $\begin{array}{l}\text { Retrospective with } \\
\text { historical controls }\end{array}$ & $\begin{array}{l}115,096 \text { Deliveries over } 10 \\
\text { years from } 1970 \text { to } 1979\end{array}$ & 1970: $\mathrm{EFM}=18 \%, \mathrm{PNM}=18 / 1,000$ \\
\hline & & & & 1979: $\mathrm{EFM}=74 \%, \mathrm{PNM}=11 / 1,000$ \\
\hline & & & & $\begin{array}{l}\text { Intrapartum death: } \mathrm{EFM}=1.5 / 1,000, \\
\text { Aus }=2.5 / 1,000, P<.005\end{array}$ \\
\hline & & & & $\begin{array}{l}\text { Neonatal death: } \mathrm{EFM}=8.1 / 1,000 \\
\text { Aus }=14.7 / 1,000, P<.001\end{array}$ \\
\hline \multirow[t]{4}{*}{ Nelson et $\mathrm{al}^{8}$} & 1996 & Case-control & $\begin{array}{l}\text { EFM abnormalities } \\
\text { compared between } 78 \\
\text { fetuses with cerebral palsy } \\
\text { and } 300 \text { controls }\end{array}$ & $\begin{array}{l}\text { Multiple late decels: OR 3.9, 95\% CI } 1.7- \\
9.3\end{array}$ \\
\hline & & & & $\begin{array}{l}\text { Decreased variability: OR } 2.7,95 \% \text { CI } \\
1.1-5.8\end{array}$ \\
\hline & & & & $\begin{array}{l}21 / 78(27 \%) \text { with cerebral palsy had EFM } \\
\text { abnormality }\end{array}$ \\
\hline & & & & $\begin{array}{l}0.2 \% \text { of children with these EFM } \\
\text { abnormalities had cerebral palsy (false } \\
\text { positive rate of } 99.8 \% \text { ) }\end{array}$ \\
\hline \multirow[t]{2}{*}{ Althaus et $\mathrm{al}^{9}$} & 2005 & Case-control & $\begin{array}{l}136 \text { Vaginal deliveries } \\
\text { (47.1\% with PVL) }\end{array}$ & $\begin{array}{l}\text { During last hour of EFM prior to delivery } \\
\text { there was no difference in total decels, } \\
\text { late decels, or decreased variability. }\end{array}$ \\
\hline & & & $\begin{array}{l}110 \text { Cesarean deliveries } \\
(55.5 \% \text { with PVL })\end{array}$ & $\begin{array}{l}\text { Significant correlation found between } \\
\text { umbilical artery base excess and number } \\
\text { of late decels }(r=-0.18, P=.01)\end{array}$ \\
\hline \multirow[t]{3}{*}{ Thacker et $\mathrm{al}^{6}$} & 2001 & $\begin{array}{l}\text { Meta-analysis of } 9 / 13 \\
\text { RCTs }\end{array}$ & $\begin{array}{l}\mathrm{N}=18,927(50 \% \mathrm{EFM}) \text { for } \\
\text { neonatal seizures and }\end{array}$ & $\begin{array}{l}\text { Neonatal seizures: RR } 0.51,95 \% \text { CI } 0.32- \\
0.82\end{array}$ \\
\hline & & & perinatal death & $\begin{array}{l}\text { Perinatal death: RR } 0.89,95 \% \text { CI } 0.60- \\
1.33\end{array}$ \\
\hline & & & $\begin{array}{l}\mathrm{N}=13,325(50 \% \mathrm{EFM}) \text { for } \\
\text { cerebral palsy }\end{array}$ & Cerebral palsy: RR $1.66,95 \%$ CI $0.92-3.00$ \\
\hline
\end{tabular}

EFM, electronic fetal monitoring; PNM, perinatal mortality; Aus, auscultation; decels, decelerations; OR, odds ratio; CI, confidence interval; RR, relative risk; PVL, periventricular leukomalacia; RCTs, randomized controlled trials.

decelerations: early, variable, and late. These early investigators agreed that fetal depression was more likely to be associated with late and severe variable decelerations, which they confirmed by measuring the $\mathrm{pH}$ of fetal scalp blood at the time of these decelerations. Late and severe variable decelerations were associated with significant reductions in mean $\mathrm{pH}$, whereas early decelerations and mild-to-moderate variable decelerations were not. ${ }^{13}$ Fetal heart rate variability was found to be an important indicator of fetal well-being, which could differentiate between fetuses with similar deceleration patterns who were more likely to be acidemic or depressed at birth. ${ }^{14}$ This research led to more specific guidelines as to how intermittent auscultation should be performed during labor. Whereas it had previously been done in a nonstandardized manner, the identification of these deceleration types led to the practice of auscultating the fetal heart rate immediately after a contraction. Electronic fetal monitoring was introduced into widespread clinical practice in the late 1960s based on retrospective studies which compared its use with historical controls where auscultation was performed in a nonstandardized manner.

In term monkey fetuses severe asphyxia was noted to lead to episodes of fetal bradycardia and hypotension associated with late decelerations. ${ }^{15}$ After prolonged survival, the cerebral damage produced by partial asphyxia in term monkey fetuses produced brain lesions that resembled closely the lesions of human perinatal injury or cerebral palsy. Because of the close similarities between the brain pathology associated with partial asphyxia in utero in the term monkey fetus and the pathology of cerebral palsy in the human, this investigator concluded that partial asphyxia in utero may play a major role in the pathogenesis of cerebral palsy in the human. He also felt that, when late decelerations are first recognized and their existence confirmed, immediate delivery of the embarrassed fetus should be considered. In 1969, it was claimed that $90 \%$ of all fetal distress is caused by umbilical 
cord compression and that electronically monitoring the entire birth process from labor to delivery could save as many as 20,000 babies a year and reduce the number of injured babies by $50 \% .^{16}$

In 1971, President Nixon's Commission on Mental Retardation adopted as a national goal "To reduce by half the occurrence of mental retardation in the United States before the end of this century." ${ }^{17}$ Most investigators felt that, because the stress of labor is clearly capable of causing fetal death, it did not seem unreasonable to assume that labor may also be a factor in producing brain damage, which is merely an intermediate point on the pathway to death. A study of 24,863 laboring patients, monitored with intermittent auscultation according to a schedule well beyond the nursing observation capabilities of most obstetric units, found there was no single reliable indicator of the fetus in trouble in terms of the FHR except with an extreme degree of terminal bradycardia, which showed the inadequacies of auscultation as a form of intrapartum surveillance..$^{18}$ Based on the assumptions that half of institutionalized individuals with severe mental retardation had causative factors directly linked to delivery and that continuous FHR monitoring during labor would reduce perinatal mortality and morbidity by $50 \%$, a cost analysis published in 1975 concluded that EFM presented attractive potentials for enhancing the quality of maternal-fetal health care and the future of its recipients, although it was acknowledged that "to date, there has been no definitive well-controlled study which has scientifically proven the value of this technique." 19

A number of studies published in the 1970s pointed to the drop in perinatal morbidity and mortality that had occurred since the introduction of EFM and attributed this to EFM. During a 10-year period from 1970 to 1979, the obstetric service at the University of Southern California found that after EFM was introduced in 1969 the perinatal mortality rate decreased as the EFM rate increased, from 18\% in 1970 to $74 \%$ in 1979 (Table 1). ${ }^{7}$ The major components of the decrease in the mortality rate were in the intrapartum and neonatal deaths. The antepartum death rate remained relatively consistent throughout the 10-year period, which the authors attributed to the lack of EFM in the antepartum period. The cesarean delivery rate increased during this period from $9.3 \%$ in 1970 to $12.3 \%$ in 1979 , but the authors did not ascribe this increase to EFM but rather to the fact that high-risk patients, who were coincidentally at higher risk for cesarean delivery, were more likely to have EFM, as well as to an increased rate of cesarean delivery for breech and premature infants during this period. A proposed large randomized controlled trial of the effect of EFM on neonatal outcome proposed for the University of Southern California-Los Angeles County Women's Hospital was rejected because it was considered unethical to withhold EFM from patients in the control arm of the study. ${ }^{20}$ In 1975 , investigators from this institution noted that, although a controlled study of a statistically adequate number of patients had not been done, given the apparent clinical usefulness of this new technology it might be ethically difficult to obtain such data. ${ }^{21}$ Studies done at the University of Southern California at this time do not mention funding from the company Corometrics, which produced the electronic fetal monitor or patents held by investigators in the studies. ${ }^{22}$ The rules involving conflict of interest were not well defined during this period.

The first randomized controlled trial of EFM did not reach the same conclusions as the earlier studies done using historical controls. In 1976, a prospective randomized study in Denver of 483 high-risk patients in labor, monitored either electronically or with intermittent auscultation, found that the cesarean rate was markedly increased in the EFM group $(16.5 \%$ versus $6.8 \%$ ), but there was no difference in neonatal death, Apgar scores, cord blood gases, or neonatal morbidity. ${ }^{23}$ The primary author had begun this randomized controlled trial because many women rejected EFM and he wished to demonstrate its usefulness to convince both women and skeptical obstetricians of its value. He was surprised to find no advantages for EFM over auscultation. ${ }^{24}$ This result was unexpected and generated controversy immediately. Although there was no significant difference in the number of patients with ominous FHR patterns (defined as late or severe variable decelerations) between the EFM and auscultation groups overall, in early labor at less than $5 \mathrm{~cm}$ dilatation, the EFM group had significantly more of these ominous findings. It was alleged that entry into the study was not masked and that more high-risk patients were assigned to the EFM group. This distinction was thought to explain the failure of EFM to decrease perinatal morbidity or mortality. ${ }^{25}$

Two epidemiologists from the Department of Health, Education, and Welfare's Office of Technology Assessment issued a review of EFM in 1978 preceded by a short report entitled "Electronic Fetal Monitoring May Do More Harm Than Good." ${ }^{26}$ They found that EFM was associated with a higher risk of infection and cesarean delivery, but no demonstrable fetal benefit, and concluded that widespread EFM use produced uncertain benefits and substantial risks at a very high cost. The report was immediately 
criticized as a government attempt to decrease health care costs by eliminating an exciting new technology, and the authors were criticized personally for never having done a residency in obstetrics (although both were trained in epidemiology and biostatistics, one of the authors had completed a residency in family practice which included clinical obstetrics) ${ }^{24}$ Prominent obstetrician advocates of EFM defended it in rebuttals published in the journals Obstetrics E Gynecology and Pediatrics. 27,28 These authors did not acknowledge the additional weight given randomized controlled trials over retrospective studies and did not accept that statisticians could review all available literature, most of which favored EFM, and not come to a conclusion favoring the routine use of EFM. ${ }^{24}$

A 1979 study combined data from 10 nonrandomized studies and concluded that "there is now compelling evidence that the intrapartum stillbirth rate will decrease by $1-2$ in 1,000, and neonatal deaths will be halved if monitoring is widely used. ...Reverence for the negative findings in the four randomized trials may be misplaced because of the grossly inadequate numbers and the unrepresentative nature of the patients." 29 This investigator believed that "most benefit would be seen in high-risk patients, especially premature babies, but that several studies suggest that low-risk patients can also benefit, probably to the extent of one life saved per 1,000." ${ }^{29}$ In the studies comparing EFM to historical controls, all the benefits in perinatal morbidity and mortality are ascribed to EFM, and no consideration is given to other factors that were changing during this period, such as the increasing use of ultrasonography, antenatal testing, legal abortion, increased obstetric surveillance, the development of the specialty of maternal-fetal medicine, and improvements in neonatal intensive care, which would decrease both fetal and neonatal mortality.

The first two decades after the introduction of EFM in the United States in the late 1960s were a period of rapid increase in litigation claiming negligent injury to the fetus during labor. In medical malpractice trials at the time, a "local standard" rule was used, which meant that scientific evidence was admissible but was considered weaker than the actual practice of respected clinicians. ${ }^{24}$ Because the routine use of EFM had become standard practice in many areas, the decision not to monitor electronically was often used in these suits as a reason to claim that malpractice had resulted in the damage. ${ }^{30}$ In 1981, a federal jury in Oklahoma City found an obstetrician guilty of medical malpractice for not using EFM in the case of a 3-year-old child with brain damage and ordered the payment of $\$ 2$ million, "the largest medical malpractice verdict in the state of Oklahoma" at that time. ${ }^{31}$ Testimony indicated that meconiumstained fluid was noted during labor, but the obstetrician continued to monitor labor by intermittent auscultation. The plaintiff's attorney argued that the presence of meconium-stained fluid indicated that the pregnancy was high risk and that EFM should have been instituted. Without EFM the child's "oxygen starvation" was not adequately diagnosed nor proper emergency treatment taken to minimize the risk of brain damage. A front-page article reporting on the trial noted that "Fetal monitors have been the subject of controversy because some experts feel they have a degree of error that can cause medical personnel to overreact, leading to what might be an unnecessary cesarean birth," ${ }^{31}$ and also that "The trial aired testimony by some of the most noted medical authorities in the country including Dr. Edward Hon, the obstetrician who invented the monitor which has become standard equipment in many hospitals." ${ }^{11}$ The plaintiff's attorney stated that the trial was significant because it was considered by experts to be the "battleground for the fetal heart monitor," and that the trial may convince hospitals to use the monitor more often. ${ }^{31}$

It was originally hoped that this new technology would help change obstetrics "from an art to a science" in identifying the compromised fetus. ${ }^{32}$ Criticisms of the early trials of EFM led to several very large clinical trials. The largest of these, performed in Dublin between 1981 and 1983, randomized 12,964 women to either EFM or auscultation. ${ }^{33}$ The cesarean delivery rate was $2.4 \%$ in the EFM group and $2.2 \%$ in the auscultation group. There were 14 stillbirths and neonatal deaths in each group, with a similar distribution of causes. There were no apparent differences in the rates of low Apgar scores, need for resuscitation, or transfer to the special care nursery. Cases of neonatal seizures and persistent abnormal neurological signs followed by survival were twice as frequent in the intermittent auscultation group, but when the nine children from the EFM group and the 21 children from the intermittent auscultation group who survived after neonatal seizures were followed up at 4 years of age, there were 3 children with cerebral palsy in each group. ${ }^{34}$ They also found that eight children from the EFM group and seven from the control group who had not had abnormal neurological signs in the neonatal period developed cerebral palsy, and that 16 of $22(78 \%)$ infants who developed cerebral palsy had no clinical evidence of intrapartum as- 
phyxia. Compared with intermittent auscultation, EFM had no protective effect against cerebral palsy.

The incidence of cerebral palsy is much higher in preterm infants. At term, the incidence of cerebral palsy is $1-2$ in 1,000 births, but at 24 weeks of gestation, $25 \%$ of survivors develop cerebral palsy. ${ }^{35}$ By studying a high-risk group of preterm infants, it was hoped that EFM would demonstrate benefit. A multicenter randomized clinical trial compared the neurologic development of 93 premature infants monitored electronically with 96 monitored by auscultation. All infants in this study were singletons, cephalic, and weighed less than $1,750 \mathrm{~g}$ at birth. ${ }^{36}$ Mental and psychomotor development were measured at three follow-up visits scheduled at 4,8 , and 18 months of age, corrected for the degree of prematurity. The incidence of cerebral palsy was higher in the group monitored electronically (20\% EFM, $8 \%$ auscultation, $P<.03)$. The median time to delivery after the diagnosis of abnormal FHR patterns was 104 minutes with EFM compared with 60 minutes with periodic auscultation. In infants weighing less than $1,750 \mathrm{~g}$ who had EFM, there was an unanticipated 2.9 -fold increase in the odds of having cerebral palsy compared with those who had periodic auscultation. This increase was observed at each of the three study hospitals. They concluded that, compared with a structured protocol of periodic fetal auscultation, EFM does not improve the neurologic development of premature infants.

A 1995 meta-analysis, performed by searching the MEDLINE database for the period 1966-1994, contacting experts, and reviewing published references, identified 12 published randomized controlled trials that examined the efficacy of EFM. ${ }^{5}$ These 12 studies included 58,855 pregnant women and their 59,324 infants in both high- and low-risk pregnancies from 10 clinical centers in the United States, Europe, Australia, and Africa. Electronic fetal monitoring was found to decrease the risk of neonatal seizures compared with auscultation. The protective effect for neonatal seizures was evident only in studies with high quality scores. No significant differences were found between the EFM and auscultation groups in 1-minute Apgar scores less than 7, admission to the neonatal intensive care unit, or perinatal death. Electronic fetal monitoring was associated with an increased rate of cesarean delivery and operative vaginal delivery. With the exception of the reduction in the rate of neonatal seizures, the use of EFM had no measurable impact on morbidity and mortality, and although the benefit in reduction of seizures was demonstrated consistently, the long-term impact of this effect was unclear because the only two studies with long-term follow-up showed that the effects of these seizures were minimal. ${ }^{34,36}$ Because of the increased morbidity associated with cesarean delivery and the lack of increased neurologic morbidity later found in children who had seizures after birth, the value of EFM in this meta-analysis was uncertain. These authors pointed out that EFM was introduced into widespread clinical practice before evidence from randomized controlled trials demonstrated either efficacy or safety and that widespread diffusion of this technology before efficacy was determined may have led to misuse, misunderstanding, and misinformation regarding malpractice litigation. ${ }^{5}$

Another meta-analysis, also published in 1995, of the randomized controlled trials comparing EFM to auscultation also found that EFM was associated with significantly higher overall rates of cesarean delivery and use of forceps and vacuum but found that, although the use of EFM did not reduce overall perinatal mortality, perinatal mortality caused by fetal hypoxia was reduced (odds ratio [OR] 0.41, 95\% confidence interval [CI] 0.17-0.98). ${ }^{4}$ Specific criteria as to how they defined fetal hypoxia were not given, and because no information regarding cord gases is given in these studies, there is no objective way to define intrapartum hypoxia-ischemia. An American College of Obstetricians and Gynecologists (ACOG) educational bulletin that reviewed intrapartum EFM pointed out that the results of this meta-analysis were based on a small number of events and were statistically unstable. ${ }^{37}$ If there had been one fewer case of perinatal death in the auscultation group, the results of the metaanalysis would not have been statistically significant. ${ }^{37}$

In a 2001 meta-analysis by the Cochrane collaboration of 13 published randomized controls trials addressing the efficacy and safety of EFM, four trials were excluded for not fulfilling selection criteria, and only one showed a significant decrease in perinatal mortality with EFM compared with intermittent auscultation (Table 1). ${ }^{6}$ This meta-analysis concluded that the routine use of continuous EFM reduced the incidence of neonatal seizures (relative risk [RR] 0.51, 95\% CI 0.32-0.82) but had no effect on the incidence of cerebral palsy (RR 1.66, 95\% CI $0.92-3.00$ ) or perinatal death (RR $0.89,95 \%$ CI $0.60-1.33)$. These investigators felt that, in view of the increase in cesarean (RR 1.41, 95\% CI 1.23-1.61) and operative vaginal delivery (RR 1.20, 95\% CI 1.11-1.30) and the lack of long-term pediatric benefit, EFM did not offer a clear advantage over ausculation. ${ }^{6}$ With one exception, ${ }^{38}$ in none of these randomized controlled trials were there prospectively defined protocols for the 
interpretation or management of abnormal FHR patterns. These randomized clinical trials may all have measured efficacy (value under optimal clinical conditions) rather than effectiveness (value in routine clinical practice), which means that the actual benefit of EFM may be even less in day-to-day obstetric practice. ${ }^{5}$

A study of 78 term singleton children born in four California counties between 1983 and 1985, who weighed at least $2,500 \mathrm{~g}$ at birth and survived to 3 years of age with the diagnosis of moderate-severe cerebral palsy, compared the electronic FHR tracings of these children with 300 randomly selected term controls (Table 1). ${ }^{8}$ Multiple late decelerations (OR 3.9, 95\% CI 1.7-9.3) and decreased beat-to-beat variability (OR 2.7, 95\% CI 1.1-5.8) were associated with an increased risk of cerebral palsy, but 57 of $78(73 \%)$ children with cerebral palsy did not have either of these abnormalities. There was no association between the highest or lowest FHR recorded for each child and the risk of cerebral palsy. The 21 children with cerebral palsy who had multiple late decelerations or decreased FHR variability on EFM represented only $0.2 \%$ of singleton infants with birth weights greater than 2,500 $\mathrm{g}$ who had these EFM findings, for a false-positive rate of $99.8 \%$. These authors concluded that specific abnormal findings on EFM were associated with an increased risk of cerebral palsy, but the false-positive rate was so high that, if these findings were used as an indication for cesarean delivery, many cesareans would have been performed without benefit but with the potential for harm. Of interest is the fact that the mothers of almost $10 \%$ of infants with cerebral palsy did not go into labor before delivery by cesarean.

In letters to the editor after the publication of Nelson's study in $1996,{ }^{8}$ some refused to believe that EFM could not do a better job of identifying fetuses that developed brain injury. A pioneer of FHR monitoring and one of the developers of the nonstress test ${ }^{39}$ the most widely used test of antenatal fetal well-being, argued that the data presented by Nelson et al were derived from 10-year-old interpretations of FHR patterns by diverse practitioners and failed to take into account newer insights into the relation of fetal behavior and neurologic injury to FHR patterns that had come to light over the previous decade (Schifrin BS, Myers SA, Cohen WR. Electronic fetal monitoring in predicting cerebral palsy [letter]. N Engl J Med 1996;335:287; [author reply] 288.). This critique of Nelson's study also stated that it made more sense to advocate greater discrimination in the evaluation of FHR patterns and not be so focused on the cesarean delivery rate. They felt that FHR patterns may indeed permit an understanding of the timing, mechanism, and preventability of injury and thus help in the planning of strategies for the prevention of cerebral palsy. Ironically, this pioneer in FHR monitoring ultimately became a well-known expert witness in medical malpractice cases and established a lucrative consulting business that he named BPM (Beats Per Minute) after the EFM findings that are usually at the heart of these cases. In a 1985 article, he wrote that "a court might well decide that the widespread utilization of EFM in low risk patients and the argument for (electronic) monitoring and against auscultation is so compelling that the ACOG and National Institute of Child Health and Human Development (NICHD) allowances (for auscultation) in the low risk patient are improper." ${ }^{40}$

Although the cesarean delivery rate has increased from $5 \%$ before the introduction of EFM to almost $25 \%$ today, the incidence of cerebral palsy in term infants has remained unchanged at $1-2$ in 1,000 births. ${ }^{41}$ Cesarean delivery during active labor, which may be performed on the basis of intrapartum EFM abnormalities, has been associated with an increased risk of hemorrhage, infection, thromboembolic events, and air or amniotic-fluid embolization. ${ }^{42,43}$ Long-term complications of cesarean delivery include an increased rate of placenta accreta and uterine rupture. When comparing the occurrence rates of cerebral palsy in nations with a broad range of cesarean rates $(7-22 \%)$, the reported cerebral palsy rates in all countries are within a very narrow range of 1.1-1.3 of 1,000 in neonatal survivors with birth weights greater than 2,500 g. ${ }^{44}$ Electronic fetal monitoring was developed to detect intrapartum asphyxia leading to cerebral palsy or death, and early studies as EFM was being developed assumed that half of all these injuries were related to intrapartum hypoxia. Later studies from multiple centers around the world have shown that, at most, $10-20 \%$ of cases of cerebral palsy in term infants are related to intrapartum hypoxia. ${ }^{45,46}$ The prevalence of the target disorder for EFM, cerebral palsy related to intrapartum asphyxia, is much lower than the overall prevalence of cerebral palsy. Because the amount of asphyxia required to cause permanent neurological damage is very near the amount that causes fetal death, the number of patients who develop cerebral palsy caused by intrapartum asphyxia is probably quite small. ${ }^{47}$ Unfortunately, debates as to whether intrapartum asphyxia caused a child's neurological disability usually take place in the courtroom.

The most obvious problem with EFM is the wide 
variability with which obstetricians interpret and respond to its findings. Numerous studies have documented the poor inter- and intraobserver reliability for the interpretation of FHR tracings. When four obstetricians reviewed 50 FHR tracings twice, only $22 \%$ were assessed identically by all four obstetricians on both occasions when trying to identify compromised infants, which made up a third of the study population. ${ }^{48}$ At the time of the second review 2 months later, the same clinicians interpreted $21 \%$ of the tracings differently, showing poor intraobserver reliability. A study in which five obstetricians independently reviewed 150 tracings found that they agreed in only $29 \%$ of the cases, showing poor interobserver reliability. ${ }^{49}$ Some investigators have stated that the failure of the randomized controlled trials to identify a benefit for EFM is related to the lack of standard definitions or management algorithms for FHR interpretation, leading to wide variability in clinical decision making. This deficiency is thought by some to have confounded the randomized trial method, suggesting that randomized trials should not be considered as grade I evidence. ${ }^{50}$ It was hoped that, if the obstetric community standardized FHR pattern interpretation and recommendations for management, with such algorithms being just as specific as the definitions of FHR patterns, then maybe a beneficial effect of EFM could be demonstrated ${ }^{51}$ Between May 1995 and November 1996, the NICHD held research planning workshops to develop standardized and unambiguous definitions for fetal heart rate tracings. ${ }^{52}$ The nationally prominent experts on this panel, all of whom had published literature on this topic, were able to reach agreement on what constitutes a reassuring FHR tracing. They were able to agree on several patterns, such as recurrent late or variable decelerations, substantial bradycardia, and absent FHR variability, which are predictive of current or impending fetal asphyxia so severe that the fetus is at risk for neurologic and other fetal damage or death. However, they acknowledged that many fetuses have FHR tracings intermediate between these two extremes and that their presumed condition and clinical management was controversial. There was no consensus within the research workshop regarding strict guidelines for clinical management using FHR patterns. It was hoped that the strict definitions for FHR patterns that they had developed could be used to devise evidence-based algorithms for management that would minimize risky interventions and reduce significant metabolic acidemia.

To determine if the new NICHD research guidelines for interpretation of FHR tracings could help us better identify fetuses at risk for neurologic morbidity, we performed a case-control study of 150 consecutive neonates with ultrasonographically diagnosed cerebral white matter injury matched by gestational age to 150 controls with normal head ultrasonograms (Table 1). ${ }^{9} \mathrm{We}$ chose to look at infants with white matter injury because this diagnosis can be made within 6 weeks of birth, unlike the diagnosis of cerebral palsy, which is not established until 1-2 years of life, potentially introducing many confounding factors, and because of the susceptibility of white matter to hypoxia and ischemia. These infants were all born at 23-34 weeks of gestation in a single institution between 1994 and 2001. We were able to obtain the FHR tracings for 125 cases (83\%) and 121 controls $(81 \%)$. The last hour of the FHR tracing before delivery was reviewed by three perinatologists blinded to outcome. Vaginal and cesarean deliveries were analyzed separately. There was no difference in baseline heart rate, tachycardia, bradycardia, shortterm variability, accelerations, reactivity, or number or types of decelerations between cases and controls in either the vaginal or cesarean delivery groups. In the vaginal delivery group, the last 16-18 minutes of the FHR tracing was uninterpretable due to difficulty in tracing the fetal heart with the fetal head low in the birth canal just before delivery. For the six infants in this study with an umbilical arterial $\mathrm{pH}$ less than 7.0 or base excess less than $-12 \mathrm{mM}$, metabolic acidosis severe enough to increase the risk of long-term neurologic morbidity, there was a significant increase in decreased short-term variability, but the positive predictive value in identifying severe metabolic acidosis was only $7.7 \%$ in this matched case-control population, which artificially enhances predictiveness by not including all normal infants. There was a significant correlation between an increasing number of late decelerations during the last hour before delivery and decreasing umbilical arterial base excess $(r=-0.18$, $P=.01$ ), but the number of late decelerations per hour was not significantly different between the severe acidosis and control groups $(1.0 \pm 1.8$ acidosis, $0.55 \pm 1.23$ controls, $P=.39$ ). Even with the use of the NICHD research guidelines for interpretation of EFM tracings, we were unable to use EFM findings to identify infants diagnosed with cerebral white matter injury within 6 weeks of birth, a major precursor of cerebral palsy.

It has been stated that computerized evaluation of FHR tracings would solve the interpretive problems produced by observer inconsistency. It was hoped that computer assistance in the quantitative processing of FHR baseline, variation, and event recognition 
would bring us one step closer to eliminating the apparently insurmountable problem of observer reliability and reproducibility. Computerized FHR analysis was introduced into routine clinical use in $\mathrm{Ox}$ ford, United Kingdom, in 1983 when it was shown that small computers could provide an objective analysis of the FHR tracing. ${ }^{53}$ These investigators concluded that measurement by a computer offers reliable objective information, from which fetal health may be assessed more objectively and accurately than by visual inspection. A prospective observational study conducted in eight tertiary medical centers in Europe and Australia of 345 women not in labor scheduled for elective cesarean delivery, whose last FHR tracing was performed within 4 hours of delivery, found that computerized quantification of accelerations and variability in the antepartum period allowed a good prediction of 1- and 5-minute Apgar scores but was not very predictive of umbilical artery $\mathrm{pH} .{ }^{54}$ A study of 51 term laboring women concluded that computer-derived FHR parameters studied during the last hour of labor did not correlate with the degree of metabolic acidosis as measured in the umbilical artery at birth. ${ }^{55}$ At this time computerized analysis of FHR tracings has failed to gain clinical acceptance because of its inability to identify the hypoxic-ischemic fetus.

\section{CONCLUSION}

Virtually all professional obstetric organizations believe that some form of monitoring is necessary during labor although there are no trials comparing either intermittent auscultation or EFM with no monitoring at all. ${ }^{47}$ The American College of Obstetricians and Gynecologists has concluded that EFM does not offer any advantage over intermittent auscultation. ${ }^{56}$ The false-positive rate of EFM in predicting adverse outcomes is high, and the use of EFM does not result in a reduction of cerebral palsy rates. ${ }^{37}$ Intermittent auscultation requires a 1:1 nurse to patient ratio and must be performed at specific intervals. Logistically, it is difficult to adhere to the ACOG guidelines for intermittent auscultation. One prospective study noted that the protocol for intermittent auscultation was successfully completed in only $3 \%$ of cases. ${ }^{57}$ Because of the difficulty and expense of performing intermittent auscultation with 1:1 nursing, EFM continues to be the most widely used method of monitoring the intrapartum fetus. Both ACOG and the Society of Obstetricians and Gynaecologists of Canada recommend some form of monitoring during labor, and EFM is easier, cheaper, and provides more data. During the first randomized controlled trial of
$\mathrm{EFM}$, the investigators noted the rise in cesarean deliveries, and at the conclusion of the study they felt that 2 of $18(6 \%)$ cesareans done for fetal distress in the EFM group would not have been done at the time they submitted their manuscript based on newer knowledge of FHR patterns..$^{23}$ They acknowledged that, based on measured infant outcome, some of their cesarean deliveries were unnecessary. This shows that EFM was being widely used as an indication for delivery before enough information was available to adequately interpret the results. Some have argued that the randomized controlled trials were conducted before the technology was sufficiently developed and that its true benefit was undervalued, ${ }^{58}$ but even with the introduction of specific guidelines for interpreting FHR tracings issued by the NICHD, inter- and intraobserver consistency remains poor, and we have still been unable to use EFM to identify the fetus at risk for neurologic morbidity. ${ }^{9}$

Since the introduction of EFM, there has been a rapid increase in litigation claiming negligent injury to the fetus during labor. Often the allegation of medical malpractice is based on the failure to perform a cesarean delivery in a timely fashion in the face of abnormal FHR patterns. Because EFM was introduced without agreed upon definitions for interpretation and management algorithms, expert witnesses retained by the opposing sides in a trial can deliver very different interpretations of the same FHR tracing in the courtroom to the confusion and frustration of lay juries. In these trials many plaintiffs' experts claim to be able to do what scientific medicine has been unable to accomplish: to identify precisely that point at which the fetus sustained irreparable brain damage. ${ }^{20}$ The benefits now claimed by the advocates of EFM are clearly more modest than originally proposed and appear to be primarily in the prevention of neonatal seizures, but since this increase in neonatal seizures has not been found to be associated with an increased risk of long-term neurologic morbidity and since the increase in operative deliveries puts the mother at some increased risk, no advantage has been proven for EFM. ${ }^{5}$ Because of the inability of EFM to identify the truly hypoxic-ischemic fetus, a joint committee from ACOG and the American Academy of Pediatrics has encouraged further research into other methods of intrapartum fetal evaluation..$^{59}$ Fetal pulse oximetry and fetal electrocardiogram wave form analysis show the most promise for improving our ability to identify the hypoxic-ischemic fetus. Both of these methods are being subjected to randomized controlled trials before their widespread introduction into clinical practice, unlike the case with EFM. In the first 
randomized controlled trial involving fetal ST waveform analysis, published in 1993, the authors stated that they believed that "this is the first time a new concept for fetal assessment that involves new technology has been tested in a randomized trial before widespread introduction into obstetric practice." ${ }^{\prime 0} \mathrm{Af}-$ ter the first randomized controlled trial of fetal pulse oximetry failed to show a decrease in the overall cesarean rate ${ }^{61}$ the ACOG Committee on Obstetric Practice stated that they could not endorse the adoption of this device at the present time because its introduction into widespread clinical practice could further escalate the cost of medical care without necessarily improving clinical outcome. ${ }^{62}$ This shows that any new intrapartum monitoring modality will be subjected to a much greater degree of scrutiny than occurred in the past with EFM.

\section{REFERENCES}

1. Martin JA, Hamilton BE, Sutton PD, Ventura SJ, Menacker F, Munson ML. Births: final data for 2002. Natl Vital Stat Rep 2003;52:1-113.

2. Edwards J, Auchard J. Four trials. New York (NY): Simon \& Schuster; 2004.

3. Wikipedia, The Free Encyclopedia. John Edwards. Available at: http://en.wikipedia.org/wiki/John_Edwards. Retrieved June 6, 2006.

4. Vintzileos AM, Nochimson DJ, Guzman ER, Knuppel RA, Lake M, Schifrin BS. Intrapartum electronic fetal heart rate monitoring versus intermittent auscultation: a meta-analysis. Obstet Gynecol 1995;85:149-55.

5. Thacker SB, Stroup DF, Peterson HB. Efficacy and safety of intrapartum electronic fetal monitoring: an update. Obstet Gynecol 1995;86:613-20.

6. Thacker SB, Stroup D, Chang M. Continuous electronic heart rate monitoring for fetal assessment during labor (Cochrane Review). In: The Cochrane Library, Issue 2, 2001. Oxford: Update Software.

7. Yeh SY, Diaz F, Paul RH. Ten-year experience of intrapartum fetal monitoring in Los Angeles County/University of Southern California Medical Center. Am J Obstet Gynecol 1982; 143:496-500.

8. Nelson KB, Dambrosia JM, Ting TY, Grether JK. Uncertain value of electronic fetal monitoring in predicting cerebral palsy. N Engl J Med 1996;334:613-8.

9. Althaus JE, Petersen SM, Fox HE, Holcroft CJ, Graham EM. Can electronic fetal monitoring identify preterm neonates with cerebral white matter injury? Obstet Gynecol 2005;105: $458-65$.

10. Little WJ. On the influence of abnormal parturition, difficult labors, premature birth, and asphyxia neonatorum, on the mental and physical condition of the child, especially in relation to deformities. Trans Obstet Soc Lond 1862;3: 293-344.

11. Hon EH. The electronic evaluation of the fetal heart rate; preliminary report. Am J Obstet Gynecol 1958;75:1215-30.

12. Caldeyro-Barcia R, Mendez-Bauer C, Posiero JJ, Escarcena LA, Pose SV, Bieniarz J, et al Control of the human fetal heart rate during labor. In: Cassels DE, editor. The heart and circulation in the newborn and infant. New York (NY): Grune and Stratton; 1966. p. 7-36.

13. Kubli FW, Hon EH, Khazin AF, Takemura H. Observations on heart rate and $\mathrm{pH}$ in the human fetus during labor. Am J Obstet Gynecol 1969;104:1190-206.

14. Paul RH, Suidan AK, Yeh S, Schifrin BS, Hon EH. Clinical fetal monitoring. VII. The evaluation and significance of intrapartum baseline FHR variability. Am J Obstet Gynecol 1975;123:206-10.

15. Myers RE. Two patterns of perinatal brain damage and their conditions of occurrence. Am J Obstet Gynecol 1972;112: 246-76.

16. Interview with Dr. Edward Hon. Watching the unborn inside the womb: high-risk mothers and the graph that raises their babies' chances. Life Magazine 1969; July 25:63-5.

17. Statement by the President on Mental Retardation. President's commission on mental retardation. Washington, DC: Department of Health, Education and Welfare. 1971.

18. Benson RC, Shubeck F, Deutschberger J, Weiss W, Berendes $\mathrm{H}$. Fetal heart rate as a predictor of fetal distress. A report from the collaborative project. Obstet Gynecol 1968;32:259-66.

19. Quilligan EJ, Paul RH. Fetal monitoring: is it worth it? Obstet Gynecol 1975;45:96-100.

20. Martin CB, Jr. Electronic fetal monitoring: a brief summary of its development, problems and prospects. Eur J Obstet Gynecol Reprod Biol 1998;78:133-40.

21. Hon EH, Petrie RH. Clinical value of fetal heart rate monitoring. Clin Obstet Gynecol 1975;18: 1-23.

22. Banta HD, Thacker SB. Policies toward medical technology: the case of electronic fetal monitoring. Am J Public Health 1979;69:931-5.

23. Haverkamp AD, Thompson HE, McFee JG, Cetrulo C. The evaluation of continuous fetal heart rate monitoring in highrisk pregnancy. Am J Obstet Gynecol 1976;125:310-20.

24. Banta HD, Thacker SB. Historical controversy in health technology assessment: The case of electronic fetal monitoring. Obstet Gynecol Surv 2001;56:707-19.

25. Stenchever MA. Discussion of "The evaluation of continuous fetal heart rate monitoring in high-risk pregnancy" by A. D. Haverkamp. Am J Obstet Gynecol 1976;125:318-9.

26. Banta HD, Thacker SB. Costs and benefits of electronic fetal monitoring: a review of the literature. Hyattsville (MD): National Center for Health Services Research; 1978.

27. Hobbins JC, Freeman R, Queenan JT. The fetal monitoring debate. Obstet Gynecol 1979;54:103-9.

28. Hobbins JC, Freeman R, Queenan JT. The fetal monitoring debate. Pediatrics 1979;63:942-51.

29. Parer JT. Fetal heart-rate monitoring. Lancet 1979;2:632-3.

30. Huber PW. Gadgets and knives. In: Galileo's revenge: junk science in the courtroom. New York (NY): Basic Books; 1993. p. $75-91$.

31. Wenske P. Doctor told to pay $\$ 2$ million. Daily Oklahoman 1981; June 17:1.

32. Hutson JM, Petrie RH. Possible limitations of fetal monitoring. Clin Obstet Gynecol 1986;29:104-13.

33. MacDonald D, Grant A, Sheridan-Pereira M, Boylan P, Chalmers I. The Dublin randomized controlled trial of intrapartum fetal heart rate monitoring. Am J Obstet Gynecol 1985;152:524-39.

34. Grant A, O’Brien N, Joy MT, Hennessy E, MacDonald D. Cerebral palsy among children born during the Dublin randomised trial of intrapartum monitoring. Lancet 1989;2: 1233-6. 
35. Goldenburg RL. Cerebral palsy. In: Creasy RK, Resnik R, editors. Maternal-fetal medicine: principles and practice. 5th ed. Philadelphia (PA): Saunders; 2004. p. 1303-24.

36. Shy KK, Luthy DA, Bennett FC, Whitfield M, Larson EB, van Belle G, et al. Effects of electronic fetal-heart-rate monitoring, as compared with periodic auscultation, on the neurologic development of premature infants. N Engl J Med 1990;322: 588-93.

37. Intrapartum fetal heart rate monitoring. Clinical Management Guidelines for Obstetrician-Gynecologists. ACOG Practice Bulletin No. 70. American College of Obstetricians and Gynecologists. Obstet Gynecol 2005;106:1453-60.

38. Westgate J, Harris M, Curnow JS, Greene KR. Randomised trial of cardiotocography alone or with ST waveform analysis for intrapartum monitoring. Lancet 1992;340:194-8.

39. Rochard F, Schifrin BS, Goupil F, Legrand H, Blottiere J, Sureau C. Nonstressed fetal heart rate monitoring in the antepartum period. Am J Obstet Gynecol 1976;126:699-706.

40. Schifrin BS, Weissman H, Wiley J. Electronic fetal monitoring and obstetrical malpractice. Law Med Health Care 1985;13: $100-5$.

41. Winter S, Autry A, Boyle C, Yeargin-Allsopp M. Trends in the prevalence of cerebral palsy in a population-based study. Pediatrics 2002;110:1220-5.

42. Lilford RJ, van Coeverden de Groot HA, Moore PJ, Bingham $\mathrm{P}$. The relative risks of caesarean section (intrapartum and elective) and vaginal delivery: a detailed analysis to exclude the effects of medical disorders and other acute pre-existing physiological disturbances. Br J Obstet Gynaecol 1990;97: 883-92.

43. Jackson N, Paterson-Brown S. Physical sequelae of caesarean section. Best Pract Res Clin Obstet Gynaecol 2001;15:49-61.

44. Clark SL, Hankins GD. Temporal and demographic trends in cerebral palsy-fact and fiction. Am J Obstet Gynecol 2003; 188:628-33.

45. Nelson KB, Ellenberg JH. Antecedents of cerebral palsy: multivariate analysis of risk. N Engl J Med 1986;315:81-6.

46. Badawi N, Kurinczuk JJ, Keogh JM, Alessandri LM, O'Sullivan F, Burton PR, et al. Antepartum risk factors for newborn encephalopathy: the Western Australian case-control study. BMJ 1998;317:1549-53.

47. Freeman RK. Problems with intrapartum fetal heart rate monitoring interpretation and patient management. Obstet Gynecol 2002;100:813-26.

48. Nielsen PV, Stigsby B, Nickelsen C, Nim J. Intra- and interobserver variability in the assessment of intrapartum cardiotocograms. Acta Obstet Gynecol Scand 1987;66:421-4.
49. Beaulieu MD, Fabia J, Leduc B, Brisson J, Bastide A, Blouin D, et al. The reproducibility of intrapartum cardiotocogram assessments. Can Med Assoc J 1982;127:214-6.

50. Parer JT, King T. Fetal heart rate monitoring: is it salvageable? Am J Obstet Gynecol 2000;182:982-7.

51. Parer JT. Electronic fetal heart rate monitoring: a story of survival. Obstet Gynecol Surv 2003;58:561-3.

52. National Institute of Child Health and Human Development Research Planning Workshop. Electronic fetal heart rate monitoring: research guidelines for interpretation. Am J Obstet Gynecol 1997;177:1385-90.

53. Dawes GS, Moulden M, Redman CW. Improvements in computerized fetal heart rate analysis antepartum. J Perinat Med 1996;24:25-36.

54. Ayres-de-Campos D, Costa-Santos C, Bernardes J. Prediction of neonatal state by computer analysis of fetal heart rate tracings: the antepartum arm of the SisPorto multicentre validation study. Eur J Obstet Gynecol Reprod Biol 2005;118: $52-60$.

55. Agrawal SK, Doucette F, Gratton R, Richardson B, Gagnon R. Intrapartum computerized fetal heart rate parameters and metabolic acidosis at birth. Obstet Gynecol 2003;102:731-8.

56. American College of Obstetricians and Gynecologists. Fetal heart rate patterns: monitoring, interpretation, and management. ACOG Technical Bulletin Number 207. Int J Gynaecol Obstet 1995;51:65-74.

57. Morrison JC, Chez BF, Davis ID, Martin RW, Roberts WE, Martin JN Jr, et al. Intrapartum fetal heart rate assessment: monitoring by auscultation or electronic means. Am J Obstet Gynecol 1993;168:63-6.

58. Paneth N, Bommarito M, Stricker J. Electronic fetal monitoring and later outcome. Clin Invest Med 1993;16:159-65.

59. American College of Obstetricians and Gynecologists, American Academy of Pediatricians. Neonatal encephalopathy and cerebral palsy: defining the pathogenesis and pathophysiology. Washington, DC: ACOG; 2003.

60. Westgate J, Harris M, Curnow JS, Greene KR. Plymouth randomized trial of cardiotocogram only versus ST waveform plus cardiotocogram for intrapartum monitoring in 2400 cases. Am J Obstet Gynecol 1993;169:1151-60.

61. Garite TJ, Dildy GA, McNamara H, Nageotte MP, Boehm FH, Dellinger EH, et al. A multicenter controlled trial of fetal pulse oximetry in the intrapartum management of nonreassuring fetal heart rate patterns. Am J Obstet Gynecol 2000;183: 1049-58.

62. Fetal pulse oximetry. Committee Opinion No. 258. American College of Obstetricians and Gynecologists. Obstet Gynecol 2001;98:523-4. 